\title{
A Study on Reinforced Concrete Columns Partially Confined with Carbon Fibre Reinforced Polymer (CFRP)
}

\author{
C. S. Lewangamage, C. K. Rankoth and M. T. R. Jayasinghe
}

\begin{abstract}
Although the use of carbon fibre reinforced polymer (CFRP) materials is considered as a very effective retrofitting technique for reinforced concrete columns, still it is the identification of cost reduction strategies that draws most of the attention since the use of CFRP materials is considered as more expensive than any other retrofitting method. Providing partial confinement in place of full confinement which is the current practice may be a viable option that allows for considerable cost savings while maintaining the required structural capacity. Although CFRP technology has been in use for several decades, some countries still do not have adequate technical know-how to use this technique effectively. As there are several design guidelines available globally, it is quite unclear which design guideline will provide an economical design while maintaining the required factor of safety. This paper presents an experimental study conducted using 17 specimens to investigate the strength increments due to external CFRP confinement of reinforced and unreinforced concrete columns. Reinforced concrete columns were provided with both full and partial confinement to study their strength and ductility increments. The volumetric ratio of CFRP was kept constant for partially confined columns to study the effect of the jacket arrangement pattern. The experimental failure loads obtained were reviewed against the theoretical values calculated using ACI and fib guidelines, to investigate the overall safety factors available when using each design guideline. The experimental results showed considerable strength and ductility increments in all of the fully and partially confined specimens. Although the volumetric ratio of CFRP was kept same for all partially confined columns, it was observed that depending on the jacket location, the strength and ductility increments would vary. It was also observed that both design guidelines give for fully confined reinforced concrete columns, a factor of safety exceeding 1.5.
\end{abstract}

Keywords: Reinforced concrete column, CFRP, partial confinement, strength, ductility

\section{Introduction}

In the modern world, the sustainability of built environments has become a key issue. One of the main strategies available for improving the sustainability of the existing built environment is the prolonging of the life of the structure while modernizing it.

There are many techniques such as steel plate bonding, external post tensioning, section enlargement and fibre reinforced polymer systems (FRP systems) for retrofitting concrete structures. Among these, FRP bonding techniques stand tall due to their versatility despite the fact that they are slightly more expensive.

There are a considerable number of studies that have been carried out on reinforced concrete column strengthening with CFRP. An experimental study has been carried out by Silva [1] to investigate the effect of the cross sectional shape of short columns on their ultimate load carrying capacities. Four types of cross sections have been considered in this study, namely circular cross sections; and square cross sections; and square cross sections with sharp corners each with $38 \mathrm{~mm}$ and $20 \mathrm{~mm}$ corner radii. It was observed that circular sectioned columns gain the highest strength increment, while those of square section with sharp corners displayed no significant improvement in their load carrying capacities, and that strength gain is increased when corner radius is increased. The same observation has been made in studies done by Carlos and Silva [2] and Tamer[3] which indicated that columns with circular cross sections can have greater ductility and strength increments.

Carlos and Silva [2] have studied the effect of the number of plies, effect of steel

\footnotetext{
Eng. (Dr.) C.S. Lewangamage, C.Eng., MIE(SL), B.Sc. Eng. (Hons) (Moratuwa), M.Eng. (Tokyo), Ph.D.(Tokyo), Senior Lecturer in Civil Engineering, University of Moratuwa.Email:sujeewal@uom.lk

Dr. C. K. Rankoth, B.Sc. Eng. (Hons) (Moratuwa), Ph.D. (Yokohama). Email:ckrankoth@gmail.com

Eng. (Prof) M.T.R. Jayasinghe, C.Eng., MIE(SL), B.Sc. Eng. (Hons) (Moratuwa), Ph.D.(Cambridge), Senior

Professor in Civil Engineering, University of Moratuwa. Email:thishan@uom.lk
} 
reinforcement and geometry of columns on columns with circular cross sections. By testing 25 different specimens, they have observed that when the column diameter is increased, the effectiveness of the external confinement gets reduced. The column with the smallest diameter has displayed the highest ultimate failure load. In the case of reinforced concrete columns with CFRP confinement, the strength of steel combined with the strength of plain concrete will provide the ultimate failure load.

It has been observed that when there is more than one ply there will be more strength, but that the strength increment will reduce when the number of plies is increased. This observation has been made through studies done by Carlos and Silva [2], and Campione[4] There are three types of fibres present, namely aramid, glass, and carbon and there have been a few studies carried out to check the most effective material type among them[1][5][6]. Most of these studies suggest that CFRP is the material that is most effective in providing strength and ductility increments.

From the study carried out by Campione[4], it has been observed that the ultimate strength will reduce when the height of the column is increased.

Turgay[7] has carried out a study on the behaviour of large scale columns with specimens partially and fully wrapped to a height of $1 \mathrm{~m}$. He has found that the failure of fully confined columns occurred near column edges, while in partially confined columns the failure was at the edges of the CFRP layers.

The load carrying capacity increment of slender columns has been studied by Pan[8]. It has been observed that when the slenderness ratio is increased, the strength increment is reduced.

The strengthening of partially deteriorated columns by providing partial confinement has been studied by Wei et al [9]. The study has shown that, providing partial confinement to strengthen partially deteriorated columns is an effective method which can introduce high strength and ductility gain for an entire column, even when the wrapping has been applied only in the deteriorated regions.

The current practice of reinforced concrete column strengthening is to wrap the entire column with CFRP, regardless of the requirement for load carrying capacity and ductility. This increases the construction cost considerably as CFRP is relatively expensive. Providing partial confinement may be one possible alteration to reduce the construction cost as it reduces the material requirement. However, only a few studies have been carried out on providing partial confinement in reinforced concrete columns, and the wellknown design guidelines on CFRP design such as ACI 440 [10] do not propose any method to allow for partial confinement.

When the standards available for FRP confinement design are considered, it can be seen that there are many countries having their own guidelines. Some of those countries are America, Japan, Canada, and Switzerland. There is a reasonable uncertainty among the designers in some countries which do not have their own design guidelines on FRP design, about the standard that would provide them with a cost effective design with a reasonable factor of safety. Hence, it is important to differentiate design aspects and the overall factors of safety for the failure loads of confined columns by considering a few well known design standards.

This paper discusses an experimental study that was carried out to ascertain the effectiveness of full and partial CFRP confinement on reinforced columns and plain concrete columns both of square cross section and an assessment of design guidelines with respect to CFRP confinement design.

The main objectives of the study were as follows:

1. To understand the following characteristics of reinforced concrete square columns confined with external CFRP jackets:

a. Strength and ductility gain due to full external confinement of reinforced and unreinforced concrete columns.

b. Behaviour of reinforced concrete columns with partial confinement.

c. Influence of the wrapping pattern of partially confined columns on strength and ductility improvements.

2. To study the existing guidelines on CFRP confinement design to identify the factor of safety of predicted load carrying capacity against the experimental results to identify the associated risk level of each design methodology proposed by ACI and fib.

In the experimental study, the strength and ductility gain for square cross sectioned columns with a single external CFRP jacket were studied. Square cross section columns were mainly selected as a large number of experimental studies have already been carried out in the past on circular sectioned columns. Besides, it is found that in actual structures square or rectangular shaped columns are more common than circular shaped columns. Hence, square and rectangular columns play 
practically a superior role than circular sectioned columns.

\section{Experimental Study}

A thorough experimental study was carried out with 17 square sectioned concrete column specimens to obtain a good understanding about the behaviour of confined short concrete columns that were subjected to an axial compression. The test specimens comprised of plain and reinforced concrete columns with full and partial external confinements.

The experimental specimens used can be mainly categorized as unreinforced and reinforced concrete columns. For unreinforced concrete columns, a total of 6 specimens were prepared which comprised of three control specimens without any CFRP confinement denoted by PL-C and three fully confined specimens denoted by PL-F. Eleven reinforced concrete columns were also prepared with three control specimens denoted by RF-C and three fully externally confined specimens denoted by RF-F. The other five specimens were confined partially, keeping the volumetric ratio of CFRP constant in all the specimens, to study the effect of the jacket arrangement pattern for ductility and strength gains. Three specimens were provided with two $75 \mathrm{~mm}$ CFRP jackets at the top and bottom of the columns and were denoted by RF-P-75mm while the other two specimens were confined with three 50mm CFRP layers at the bottom and middle of the specimens and denoted by RF-P-50mm. The specimen types are shown in Figure 1 and Figure 2.

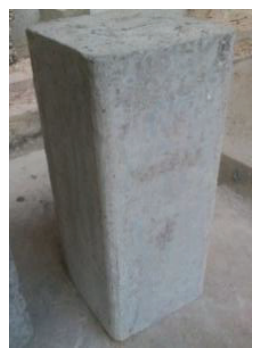

(a)

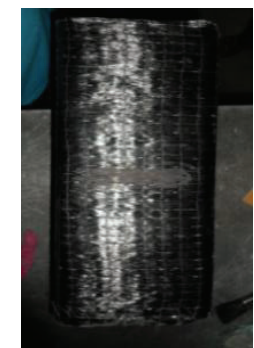

(b)
All the specimens had the dimensions $150 \times 150$ $\times 350 \mathrm{~mm}$. When providing CFRP confinement for reinforced concrete columns, stress concentration at the corners should be avoided to prevent premature failure of CFRP. Based on $\mathrm{ACI}[10]$ guidelines, the corners of every specimen were provided with a chamfer having a corner radius of $15 \mathrm{~mm}$. The reinforced concrete columns consisted of 4T10 main reinforcement with a yield strength of 460 $\mathrm{N} / \mathrm{mm}^{2}$ and links at $100 \mathrm{~mm}$ spacing with $\mathrm{R} 6$ bars with a yield strength of $250 \mathrm{~N} / \mathrm{mm}^{2}$. The reinforcement arrangement of the test specimens and sections is shown in Figure 3.

Tyfo SCH 41 fibre and the recommended epoxy mix were used for CFRP bonding. The properties of epoxy binder and the properties of composite CFRP laminate are shown in Table 1. Data related to vertical load vs. deformations and vertical average stress vs. strain variations at selected locations were measured during testing. Strain gauge locations are shown in Figure 4. Strain gauge length was selected as $60 \mathrm{~mm}$ in accordance with the studies carried out by Brandon and Hamilton [11]. The recommended strain gauge length for the measurement of strains in concrete surfaces is 2.5 times the maximum aggregate size of the concrete. The same gauge length was used for the measurement of strains over the CFRP laminates.

In reinforced and plain specimens, horizontal and vertical strains at two perpendicular locations at the mid heights of the columns were measured for both control and fully confined columns.

Figure 1 - Plain concrete test specimens, (a) control specimens, (b) Fully confined specimens

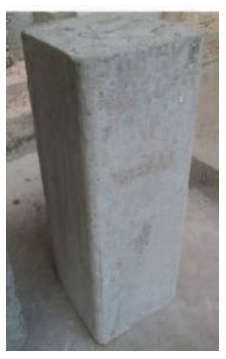

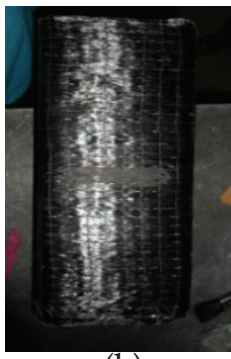

(b)

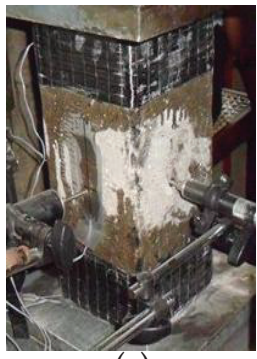

(c)

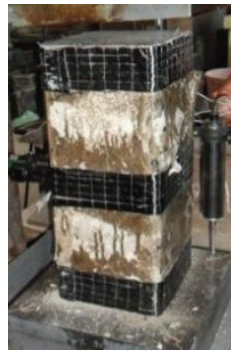

(d)

Figure 2 - Reinforced concrete test specimens, (a) control specimens, (b) Fully confined specimens (c) partially confined RF-P-75mm specimens (d) partially confined RF-P-50mm 
In partially confined columns RF-P-75mm, the vertical strain and the horizontal strain at the concrete surface at mid height along with the horizontal strain of the CFRP layer were measured while for RF-P-50mm specimen, the horizontal strains at the middle of the CFRP layers and at one concrete surface at the middle of that portion were measured. All the specimens were tested for axial compression in

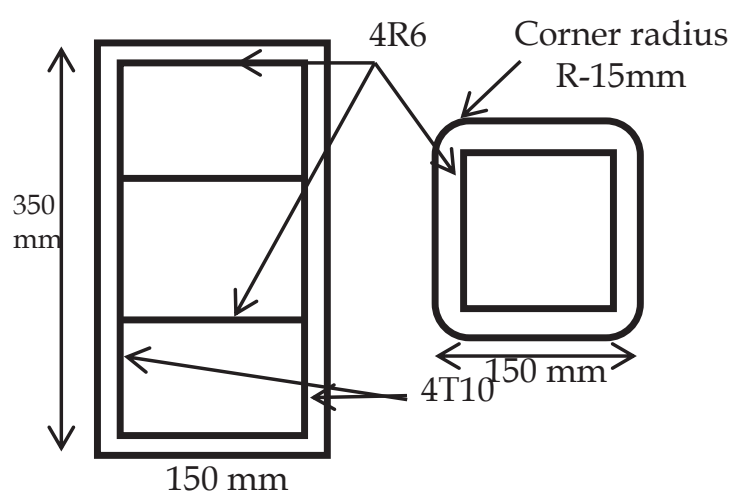

Figure 3 - Reinforcement arrangement of the specimens

Table 1 - Properties of epoxy and Gross Laminates

\begin{tabular}{|l|l|l|}
\hline Parameter & $\begin{array}{l}\text { Epoxy } \\
\text { properties }\end{array}$ & $\begin{array}{l}\text { Gross } \\
\text { laminate } \\
\text { properties }\end{array}$ \\
\hline $\begin{array}{l}\text { Ultimate } \\
\text { tensile strength }\end{array}$ & $72.4 \mathrm{MPa}$ & $72.4 \mathrm{MPa}$ \\
\hline $\begin{array}{l}\text { Elongation at } \\
\text { break }\end{array}$ & $5.0 \%$ & $5.0 \%$ \\
\hline $\begin{array}{l}\text { Tensile } \\
\text { Modulus }\end{array}$ & $3.18 \mathrm{GPa}$ & $3.18 \mathrm{GPa}$ \\
\hline $\begin{array}{l}\text { Flexural } \\
\text { strength }\end{array}$ & $3.12 \mathrm{GPa}$ & $3.12 \mathrm{GPa}$ \\
\hline
\end{tabular}

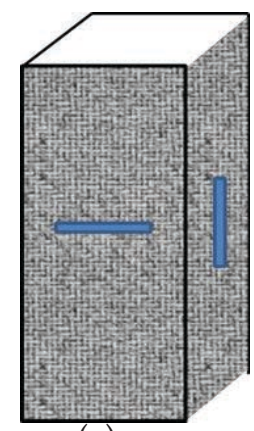

(a)

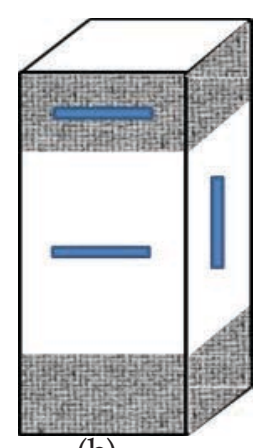

(b)

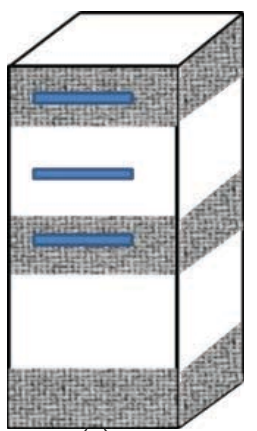

(C)
Figure 4 - Strain gauge locations for test specimens, (a) Control specimen and fully confined specimens (b) for RF-P-75mm specimens (c) RF-P-50mm specimens a testing machine with a $2000 \mathrm{kN}$ capacity. The loading arrangement is shown in Figure 5.
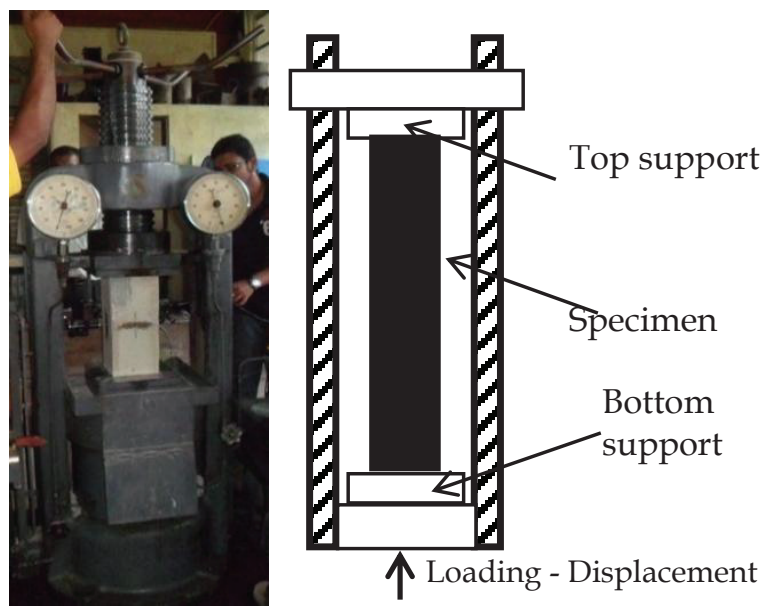

Figure 5 - Loading arrangement

\section{Experimental Results}

The behaviour of specimens was identified through a few parameters, namely failure mode, failure load, ductility ratio, and stress strain variation. Failure mode is the characteristics of the failure observed at ultimate load, failure load is the maximum load that the specimen can undergo up to the time of the failure, and the ductility ratio used to study the ductile behaviour is the ultimate displacement at the time of failure divided by specimen height. The measured stress strain variations were observed for each type of specimen.

It was observed that both reinforced and plain concrete control specimens failed due to crushing of concrete. In both fully confined reinforced concrete and plain concrete columns, the failure occurred due to the rupture of the CFRP layer at mid height of the column. In partially confined columns, the failure occurred due to crushing of concrete in between the CFRP layers. Failure modes observed for each type of specimens are shown in Figure 6 and Figure 7.

Since no horizontal cracks were observed, it could be concluded that the failure was not due to flexure. Failure loads and ductility ratio values of the test specimens are summarized in Table 2. It can be observed that in reinforced concrete columns, the maximum failure load and ductility ratio are obtained for fully confined columns, while the partially wrapped columns show a higher failure load and a considerable ductility increment with respect to the control specimens. 

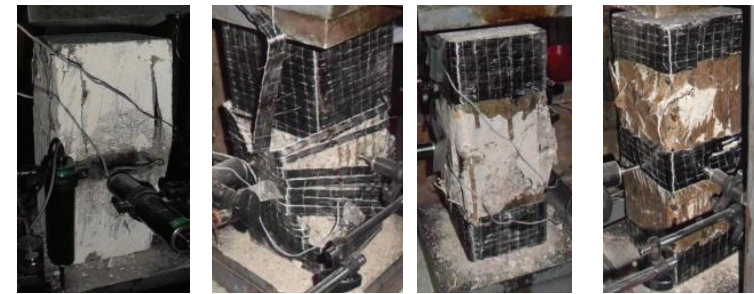

Figure 6 - Failure modes of reinforced concrete specimens
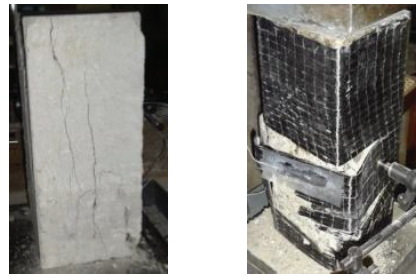

Figure 7 - Failure modes of plain concrete columns

As for the plain concrete specimens, fully confined columns show a considerable increment of failure load and ductility ratio with respect to the control specimens.

Table 2 - Average failure loads and ductility ratio values

\begin{tabular}{|c|c|c|c|}
\hline Specimen & $\begin{array}{c}\text { Average } \\
\text { failure } \\
\text { load } \\
\text { (kN) }\end{array}$ & $\begin{array}{c}\text { Failure } \\
\text { load } \\
\text { increment }\end{array}$ & $\begin{array}{c}\text { Average } \\
\text { ductility } \\
\text { ratio }\end{array}$ \\
\hline \multicolumn{4}{|c|}{ Reinforced concrete columns } \\
\hline RF-C & 571.6 & - & 5.6 \\
\hline $\begin{array}{c}\text { RF - P - } \\
50 \mathrm{~mm}\end{array}$ & 1044.8 & $83 \%$ & 7.5 \\
\hline $\begin{array}{c}\text { RF - P - } \\
\text { 75mm }\end{array}$ & 909.1 & $59 \%$ & 10 \\
\hline RF-F & 1144.5 & $100 \%$ & 12.7 \\
\hline \multicolumn{4}{|c|}{ Plain concrete columns } \\
\hline PL - C & 598.5 & - & 6.5 \\
\hline PL - F & 879.6 & $47 \%$ & 9.8 \\
\hline
\end{tabular}
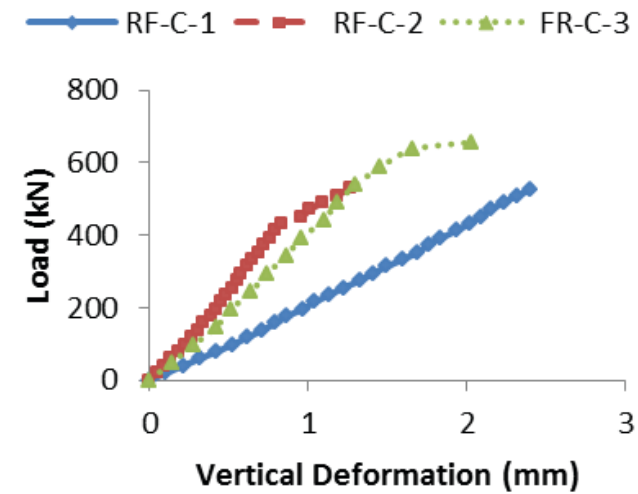

(a)
When the percentage increment of the failure load is considered, it is found that in plain concrete fully confined column, the increment as $47 \%$ with respect to plain control specimens and that in reinforced fully confined columns, the increment was $100 \%$. In partially confined columns also, a considerable strength increment could be observed as shown in Table 2. The important fact to be noted here is that although the amount of CFRP material has been same in both RF-P-75mm and RF-P$50 \mathrm{~mm}$ specimens, the percentage increments of the respective failure loads considerably differ in the two specimen types. From this observation, it can be concluded that the wrapping pattern of the CFRP jacket has a considerable effect on the failure load of partially confined columns.

From the ductility ratio variation, it is evident that in fully wrapped plain concrete columns, there is a considerable ductility increment with respect to the control specimens. In reinforced concrete columns, it can be observed that higher the failure load, the higher is the ductility ratio. A very important fact to be noticed from the current study is that the ductility ratio of the tested short columns was defined simply as the ultimate vertical displacement at the time of failure divided by the specimen height. This definition is different from the conventional definition of ductility which is based on the moment and curvature of the column cross section. Hence, the values obtained cannot be directly compared with the limit values recommended in the standard specifications.

The stress strain variations of the test specimens are shown in Figure 8 to Figure 12.

There is a noticeable variation of the load deformation of sample RF-C-1 in Figure 8(a).This may be due to some non-uniformity of the sample that was present during casting, although it was not visible on the outer surfaces.

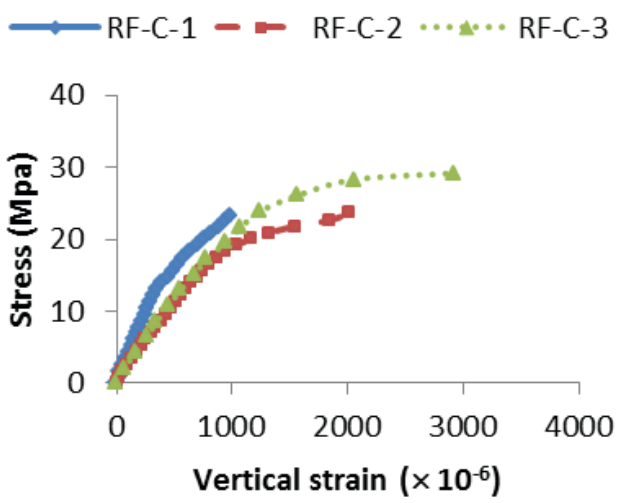

(b)

Figure 8 - Measured quantities for RC-C specimens (a) load deformation variation (b) stress strain variations 

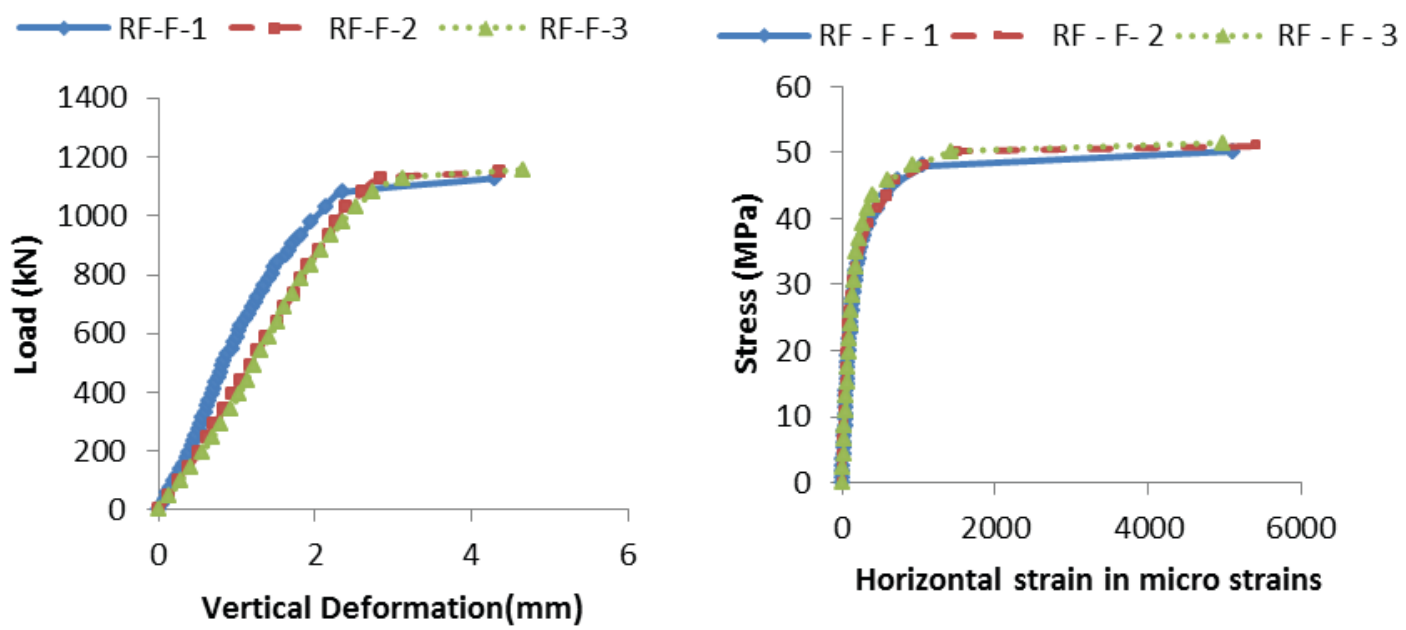

Figure 9 - Measured quantities for RF-F specimens (a) load deformation variation (b) stress strain variations
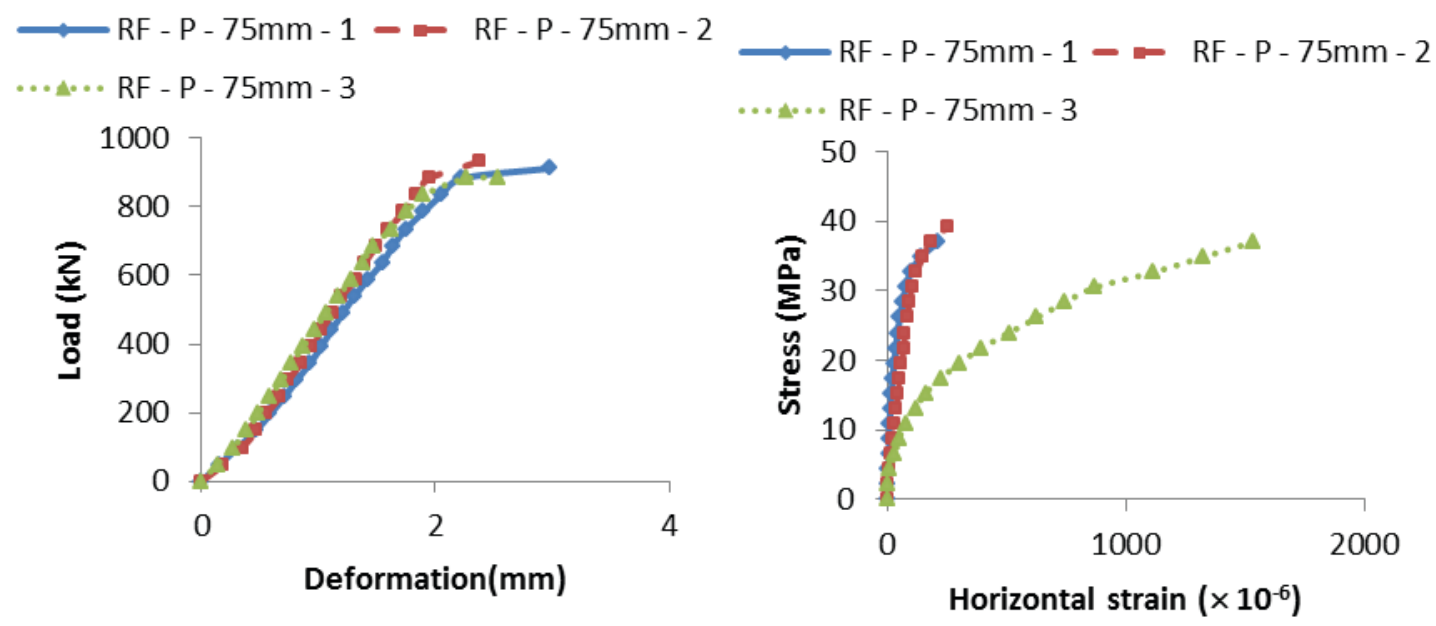

Figure 10 - Measured quantities for RF-P-75mm specimens (a) load deformation variation (b) stress strain variations

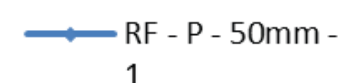

1

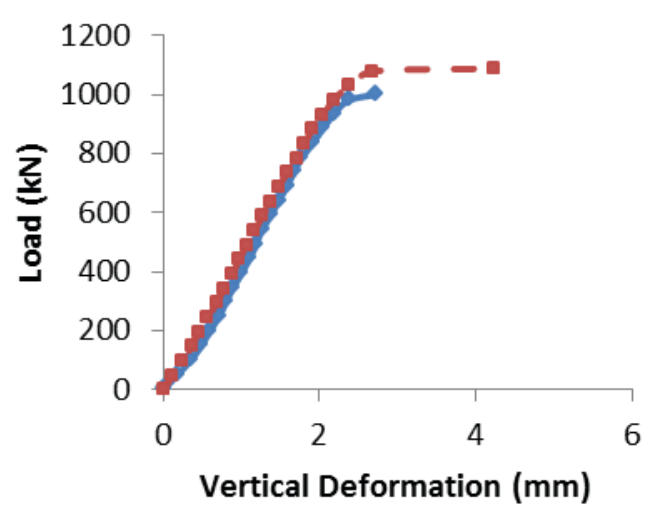

$\longrightarrow$ RF - P - 50mm - 1 BOTTOM

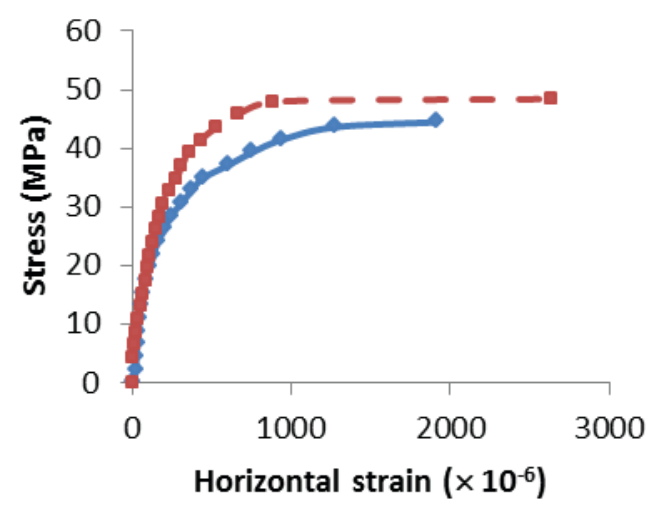

Figure 11 - Measured quantities for RF-P-50mm specimens (a) load deformation variation (b) stress strain variations 

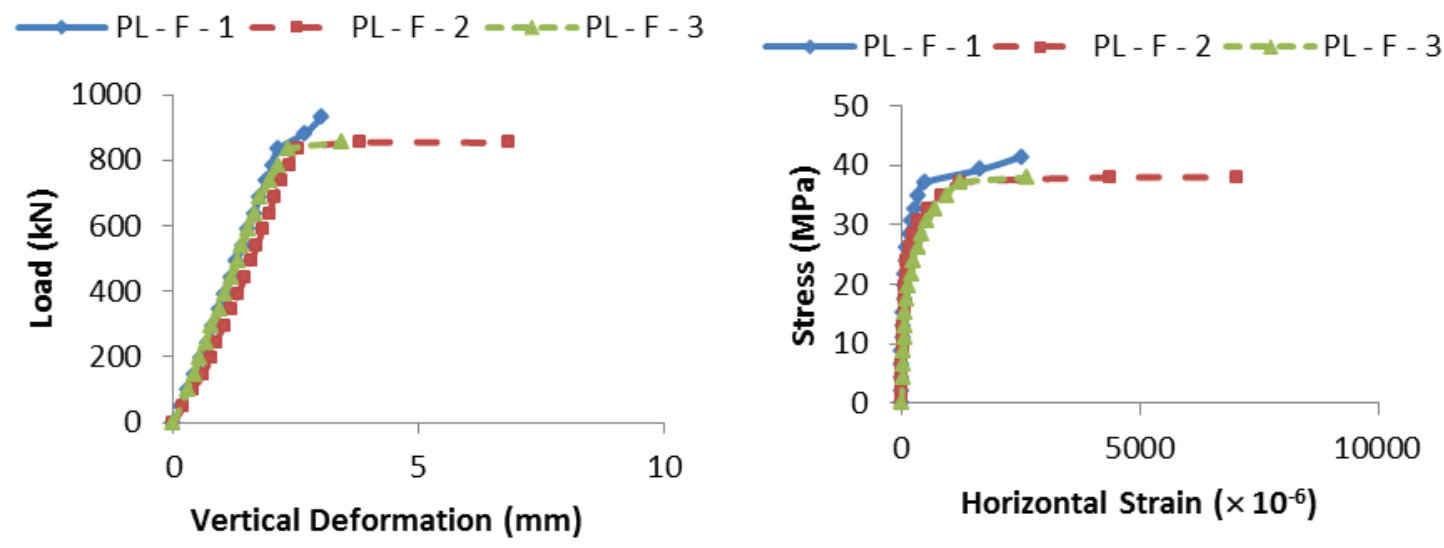

\section{Figure 12 - Measured quantities for RC-C specimens (a) load deformation variation (b) stress strain variations}

The experimental behaviors of horizontal and vertical strains against vertical stresses of all three specimens shown in Figure 9 indicate variation patterns that are similar with no noticeable deviations. The strain increment in the plastic range is clearly visible in the horizontal strain diagrams.

It can be seen that the load deformation curves of the three specimens show the same behavior pattern, while the stress strain variation in one specimen deviates considerably from those of the other two. This may be due to a localized effect near the strain gauge.

It can be observed that the overall stress strain behaviours of the two specimens are very similar while the failure strains of the two specimens are different. The reason for this could be that since the strain is measured near the point of failure in micro strains, the rate of change of strain can be greater because of the considerable delay that can occur when taking readings manually.

\section{Study on Design Guidelines}

Two major design guidelines were reviewed under this study, namely ACI 440.2R-8[10] of the American Concrete Institute and the fib Bulletin 14[12] of the International Federation for Structural Concrete, Switzerland. The major difference between the two guidelines is that in ACI design standards many safety factors have been introduced for various uncertainties of failures where as the fib Bulletin 14[12] has not introduced values for any special factor of safety for CFRP behaviour using only Euro Code[13] specified material safety factors for both concrete and CFRP.

\section{a. Design According to ACI 440}

The ultimate compressive strength of the column after it has been strengthened should be calculated according to Equation 1.

$\emptyset_{p n}=0.8 \emptyset\left[0.85 f_{c c}^{\prime}\left(A_{g}-A_{s t}\right)+f_{y} A_{s t}\right]$
$A_{g}$ is the gross cross sectional area of the concrete column and $A_{s t}$ is the area of the longitudinal steel. $\emptyset p_{n, r e q}$ is the required ultimate strength of the strengthened column. Yield strength of steel is denoted as $f_{y}$. The compressive capacity of confined concrete can be calculated from Equation 2.

$f_{c c}^{\prime}=f_{c}^{\prime}+\varphi_{f} 3.3 k_{a} f_{l}$

where $k_{a}$ is a constant which depends on the cross sectional dimensions of the concrete column and $f_{c}^{l}$ is the unconfined compressive strength of concrete. $f_{l}$ is the lateral confining pressure which can be calculated from Equation 3.

$f_{l}=\frac{2 E_{f} n t_{f} \varepsilon_{f e}}{D}$

$\varphi_{f}$ is a reduction factor stated by the ACI 440 committee having a value of 0.95 and $\varepsilon_{f e}$ can be calculated using Equation 4.

$\varepsilon_{f e}=k_{\varepsilon} \varepsilon_{u e}$

$k_{\varepsilon}$ is an experimental safety factor which allows for the premature failure of CFRP. ACI, based on experimental studies, has recommended a value of 0.55 for this safety factor. $E_{f}$ is the young's modulus of CFRP. $t_{f}$ is the thickness of the CFRP layer. The design values of ultimate strain and the strength capacity of FRP materials should be calculated after reducing for environmental effects, making use of data given in Table 9.1 of the code [10].

$f_{f u}=C_{E} f_{f u}^{*}$

$\varepsilon_{f u}=C_{E} \varepsilon_{f u}^{*}$

$f_{f u}, \varepsilon_{f u}$ in Equations 5 and 6 are the design ultimate stress and strain where, $f_{f u}^{*}, \varepsilon_{f u}^{*}$ are the actual ultimate stress and strain of the CFRP material and $C_{E}$ is the environmental reduction factor.

$k_{a}$ can be calculated from Equation 7

$k_{a}=\frac{A_{e}}{A_{c}}\left(\frac{b}{h}\right)^{2}$

$A_{e}$ is the effective confined area of the concrete section and $A_{c}$ is the cross sectional area of the concrete column. $\mathrm{b}$ and $\mathrm{h}$ are the lowest and 
highest cross sectional dimensions of the rectangular column section as defined in Figure 13. The area ratio can be calculated from Equation 8. $r_{c}$ is the corner radius and $\rho_{g}$ is the volumetric ratio of longitudinal steel.

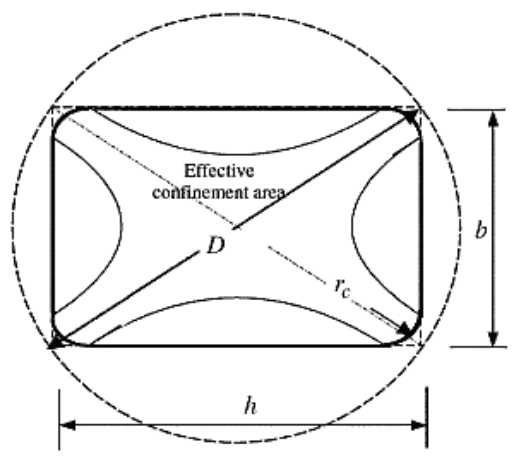

Figure 13 - Parameters for ACI design calculations

$\frac{A_{e}}{A_{c}}=\frac{1-\frac{\left[\left(\frac{b}{h}\right)\left(h-2 r_{c}\right)^{2}+\left(\frac{h}{b}\right)\left(b-2 r_{c}\right)^{2}\right]}{3 A_{g}}-\rho_{g}}{1-\rho_{g}}$

\section{b. Design According to fib Bulletin 14}

The design calculation is based on calculating the lateral confinement pressure due to external CFRP jacketing. Figure 14 explains the lateral confinement pressure from the CFRP jacket along with jacket stress.

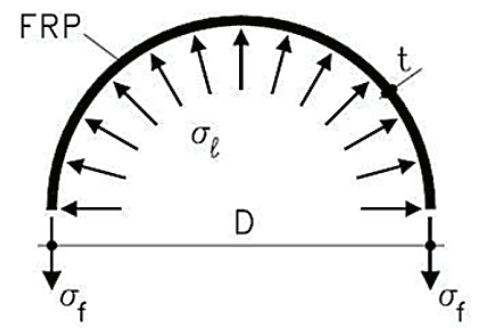

Figure 14 - Lateral confining stress and CFRP jacket stress

$\sigma_{l}$ is the lateral confining pressure exerted by the CFRP jacket and $\sigma_{f}$ is the jacket stress in the hoop direction. The design procedure starts with the calculation of the ultimate confining stress $f_{l}$ due to the CFRP jacket and can be calculated from Equation 9.

$f_{l}=\frac{1}{2} \rho_{j} f_{j}=\frac{2 t_{j} f_{j}}{d_{j}}$

$f_{j}$ is the ultimate strength of the CFRP jacket and $\rho_{j}$ is the volumetric ratio of CFRP. $\rho_{j}$ can be indicated in terms of jacket thickness $t_{j}$ and equivalent diameter of the column cross section $d_{j}$. The fib strength calculation process is based on a downward curve for the stress strain variation of the confined column. Hence, the failure load of the column will be less than the maximum load that column will encounter until it fails. The peak load, $f_{c c}$ and the peak strain, $\varepsilon_{c c}$ can be calculated from Equations 10 and 11 respectively.

$$
\begin{aligned}
& f_{c c}=f_{c o}\left(2.254 \sqrt{1+7.94 \frac{f_{l}}{f_{c o}}}-2 \frac{f_{l}}{f_{c o}}-1.254\right) \ldots \\
& \varepsilon_{c c}=\varepsilon_{c o}\left[1+5 .\left(\frac{f_{c c}}{f_{c o}}-1\right)\right]
\end{aligned}
$$

The term $f_{c o}$ is the unconfined compressive strength of concrete taken as $20 \mathrm{MPa}$ for the calculation and $\varepsilon_{c o}$ is the cracking strain of concrete for which the value is taken as 0.002 . Then, the failure load $f_{c u}$, and failure strain $\varepsilon_{c u}$ can be calculated from Equations 12 and 13 .

$f_{c u}=\frac{E_{c} \varepsilon_{c u}}{1+2 \beta \varepsilon_{j u}}$

$\varepsilon_{c u}=\varepsilon_{c c}\left(\frac{2 \beta \varepsilon_{j u} E_{c c}}{E_{c}-E_{c c}}\right)^{1-E_{c c} / E_{c}}$

$E_{c}$ is the elastic modulus of concrete. $\varepsilon_{j u}$ is the ultimate failure strain of the CFRP jacket. According to the specifications of the manufacturer, this value is $1 \%$ for Tyfo SCH41. $E_{c c}$ and $\beta$ can be calculated from Equations 14 and 15 .

$E_{c c}=f_{c c} / \varepsilon_{c c}$

$\beta=\frac{5700}{\sqrt{f_{c o}}}-500$

$f_{i}$ should be modified for non-circular sections and partial confinement as set out in the guidelines. The modification factor for rectangular or square columns with corner radii can be calculated using Equation 16 and the terms used are elaborated in Figure 15.

$k_{e}=1-\frac{b^{2}+d \prime^{2}}{3 A_{g}\left(1-\rho_{s g}\right)}$

$\rho_{s g}$ is the volumetric ratio of CFRP and $A_{g}$ is the gross cross sectional area.

The modification factor for partial confinement can be calculated from Equation 17 and the symbols used are illustrated in Figure 16.

$k_{e}=\frac{\left(1-\frac{s \prime}{2 D}\right)^{2}}{1-\rho_{s g}} \approx\left(1-\frac{s \prime}{2 D}\right)^{2}$

The important fact to be noted here is that in the fib design calculation procedure, no safety factors have been introduced. The design load carrying capacity should be calculated according to EC2. The axial load carrying capacity of a short column, $N_{R d}$, can be calculated from Equation 18 in accordance with Euro Code 2 [13].

$\mathrm{N}_{\mathrm{Rd}}=0.567 \times \mathrm{f}_{\mathrm{ck}} \times \mathrm{A}_{\mathrm{c}}+0.87 \times \mathrm{f}_{\mathrm{yk}} \times \mathrm{A}_{\mathrm{s}}$

$f_{c k}$ is the unconfined compressive strength of concrete. In this case, the ultimate failure stress $f_{y k}$ is the strength of longitudinal steel reinforcement. $A_{c}$ and $A_{s}$ are the area of concrete and area of steel of the column respectively. 


\section{c. Comparison of Experimental Results with Design Guideline Results}

The values obtained from design calculations and their comparison with experimental results of both ACI and fib guidelines are shown in Table 3.

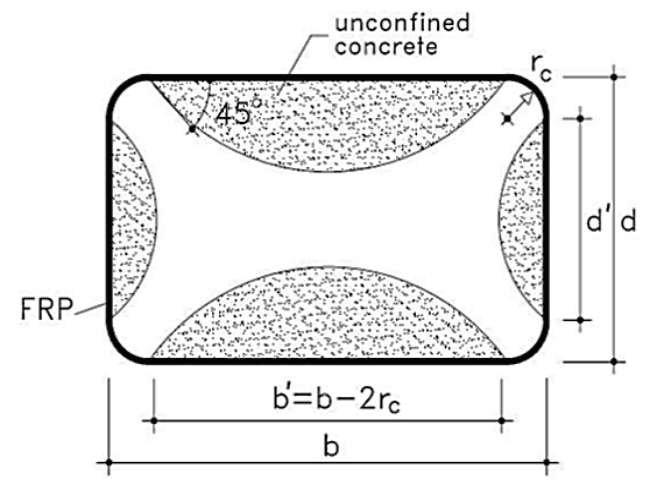

Figure 15 - Definition of terms for Equation 16

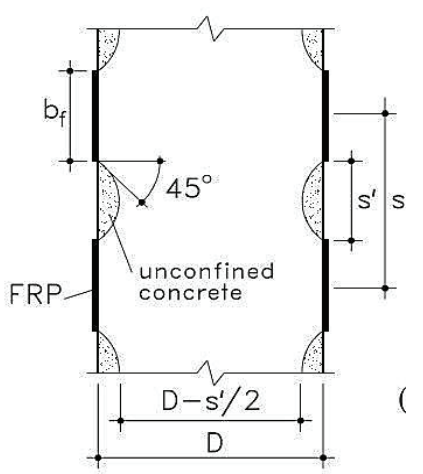

Figure 16 - Modification for partial confinement

Table 3 - Comparison of experimental results with design calculations

\begin{tabular}{|c|c|c|c|}
\hline Specimen & $\begin{array}{c}\text { Design } \\
\text { load } \\
\text { carrying } \\
\text { capacity } \\
(\mathrm{kN})\end{array}$ & $\begin{array}{c}\text { Experimental } \\
\text { load carrying } \\
\text { capacity } \\
(\mathrm{kN})\end{array}$ & $\begin{array}{c}\text { Factor } \\
\text { of } \\
\text { safety }\end{array}$ \\
\hline \multicolumn{4}{|c|}{ ACI 440.2R-8 } \\
\hline RF - F & 331.2 & 1144.5 & 3.46 \\
\hline RF - F & 703.6 & 1144.5 & 1.63 \\
\hline $\begin{array}{c}\text { RF - P75 } \\
\text { mm }\end{array}$ & $\begin{array}{c}450.33 \\
\text { Fib bulleting 14 }\end{array}$ & 2.02 \\
\hline RF - P 50 & 500.6 & 1044.8 & 2.09 \\
\hline
\end{tabular}

It can be observed that there is a large factor of safety of about 3.5 available when ACI design criterion is used for the CFRP design in comparison to fully confined concrete columns, while the factor of safety for fully confined specimens, according to fib guidelines has a value of only 1.6 and for partially confined columns this factor of safety is about 2.0. When the values for the factor of safety available from the ACI design guidelines and the fib design guidelines are considered for fully confined columns, it is obvious that ACI design guidelines are more conservative. Hence, depending on the risks involved with the project concerned, the designer can choose the guideline to be adopted.

\section{Conclusions}

An experimental study and a design guideline review was done on CFRP strengthened reinforced and plain concrete columns. The behavior of partially confined columns was studied as it provides a cost effective option, compared to the current system of providing full confinement for all the columns, regardless of the required strength increment. Two major CFRP design systems, ACI and fib were considered for the design guideline review and the design strengths calculated were compared with experimental results. The major conclusions drawn from the study could be listed as follows:

1. It was observed that with respect to the failure load of every column that had any kind of external confinement, the experimental failure load has a considerable increment with respect to that of the corresponding control specimen. Hence, the load carrying capacity of short columns can be increased significantly for both plain and reinforced concrete columns by providing full or partial confinement.

2. The strength increment for RC columns is higher than for plain concrete columns with full external confinement with a single CFRP jacket. The load carrying capacity increment for fully confined reinforced concrete columns was $100 \%$, while for fully confined plain concrete columns the strength increment was $47 \%$. The reason for the higher strength gain of reinforced concrete is due to the reduction of the lateral strain in RC columns as a result of steel reinforcement.

3. When partially confined columns are considered, the strength increment of 
columns with two $75 \mathrm{~mm}$ wrappings showed an increment of about $59 \%$, while specimens with three $50 \mathrm{~mm}$ wrappings showed an increment of $83 \%$ with respect to reinforced concrete control specimens. When two partially confined columns are compared, the specimens with three $50 \mathrm{~mm}$ wraps showed 15\% increment with respect to two $75 \mathrm{~mm}$ wrapped specimens. This clearly indicates that there is a considerable influence of the wrapping pattern on the strength increment of partially wrapped columns as well as the volumetric ratio of CFRP.

4. Ductility improvement was calculated according to ductility ratio. In plain concrete columns, ductility was considerably higher than in the control specimens.

5. With respect to the ductility of reinforced concrete specimens, the lowest ductility was shown in the control specimens, while the highest ductility was obtained in the fully wrapped specimens. The ductility of partially wrapped columns was in between those two values. It was observed that the ductility was increasing in proportion to the ultimate strength increment. The specimens with higher failure loads showed a higher ductility ratio.

6. The load carrying capacity calculated from ACI has a safety factor about 3.5 and from fib report calculation, it gets a value of 1.6 for fully confined columns. The designer can choose one of the two depending on the risk allowed for a particular project.

7. The factor of safety for partially confined columns using fib calculation process showed a value greater than 2.0 for both types of partially confined columns and this can be used for design calculations with a reasonable factor of safety.

\section{Acknowledgement}

This research was supported by Senate Research Grant Number SRC/LT/2011/26 of the University of Moratuwa. The authors would wish to specially thank NAVCORP, Sri Lanka for providing CFRP materials for this study.

\section{References}

1. Silva, M. A. G., "Behavior of Square and Circular Columns Strengthened with Aramidic or Carbon Fibers," Construction and Building Materials, vol. 25, no. 8, pp. 3222-3228, Aug. 2011.
2. Chastre, C., and Silva, M. A. G., "Monotonic Axial Behavior and Modelling of RC Circular Columns Confined with CFRP," Engineering Structures, vol. 32, no. 8, pp. 2268-2277, Aug. 2010.

3. Maaddawy, T. E., Sayed, M. E., and Abdel-Magid, B., "The Effects of Cross-Sectional Shape and Loading Condition on Performance of Reinforced Concrete Members Confined with Carbon FiberReinforced Polymers," Materials \& Design, vol. 31, no. 5, pp. 2330-2341, May 2010.

4. Campione, G., "Influence of FRP Wrapping Techniques on the Compressive Behavior of Concrete Prisms," Cement and Concrete Composites, vol. 28, no. 5, pp. 497-505, May 2006.

5. Tastani, S. P., and Pantazopoulou, S. J., "Experimental Evaluation of FRP Jackets in Upgrading RC Corroded Columns with Substandard Detailing," Engineering Structures, vol. 26, no. 6, pp. 817-829, May 2004.

6. Rousakis, T. C., Karabinis, A. I., and Kiousis, P. D., "FRP-Confined Concrete Members: Axial Compression Experiments and Plasticity Modelling," Engineering Structures, vol. 29, no. 7, pp. 1343-1353, Jul. 2007.

7. Turgay, T., Polat, Z., Koksal, H. O., Doran, B. and Karakoç, C. "Compressive Behavior of Large-Scale Square Reinforced Concrete Columns Confined with Carbon Fiber Reinforced Polymer Jackets," Materials E Design, vol. 31, no. 1, pp. 357-364, Jan. 2010.

8. Pan, J. L., Xu, T., and Hu, Z. J, "Experimental Investigation of Load Carrying Capacity of the Slender Reinforced Concrete Columns Wrapped with FRP," Construction and Building Materials, vol. 21, no. 11, pp. 1991-1996, Nov. 2007.

9. Wei, H., Wu, Z., Guo, X., and Yi, F., “Experimental Study on Partially Deteriorated Strength Concrete Columns Confined with CFRP," Engineering Structures, vol. 31, no. 10, pp. 2495-2505, Oct. 2009.

10. ACI Committee 440, Guide for the design and construction of externally bonded FRP systems for strengthening concrete structures. Detroit: American Concrete Institute, 2002.

11. Ross, B. E., and H. R. (Trey) Hamilton III, "Evaluation of Strain Gauge Lengths for Testing Limestone and Granite Aggregate Concretes," Construction and Building Materials, vol. 25, no. 1, pp. 406-408, Jan. 2011.

12. "Fib bulletin 14 -Externally bonded FRP Reinforcement for RC Structures" Task Group 9.3, The International Federation for Structural Concrete. 2001.

13. “BS EN 1992-1-1:2004 - Eurocode 2: Design of Concrete Structures - Part 1-1: General Rules and Rules for Buildings." British Standards Institute. 